\title{
DELAMINATION PREDICTION BY CONTINUUM DAMAGE MECHANICS
}

\author{
O. ALLIX*, L. GORNET, P. LADEVĖZE, D. LÉVÊQUE \\ Laboratoire de Mécanique et Technologie \\ ENS de Cachan, CNRS, Université Paris VI \\ 61 av. Président Wilson, 94230 Cachan, France \\ * Also at Université d'Evry-Val-d'Essonne/ IUT GMP \\ 2 cours Monségnieur Roméro, 91000 Evry Cédex -France
}

\begin{abstract}
The present study describes the basic principles of a general damage approach for laminates and demonstrates its prediction possibilities for simulating the complete fracture phenomenon in the case of the initiation and propagation of delamination. In this paper, the Damage Mechanics Approach is presented to solve delamination problems such as the propagation of an initiated crack or the initiation of delamination around holes. For the M55J/M18 carbon/epoxy material, numerical simulations are presented and compared with experimental results.
\end{abstract}

\section{Introduction: the meso-modelling concept}

Delamination often appears as the result of the interaction between different damage mechanisms, such as fiber breaking, transverse micro-cracking and the debonding of adjacent layers itself. Our aim herein is to build a bridge between damage mechanics and delamination by including all these damage mechanisms within the delamination analysis. To perform this, a damage meso-model, which allows us to predict both delamination initiation and propagation far more precisely, has been defined. Thanks to the proposed approach, both initiation and propagation are included in a single model. 
An initial step, which has been conducted in other studies, was to model the laminate as a stacking sequence of non-linear layers and non-linear interlaminar interfaces (see Figure 1). At the layer level, the inner damage mechanisms are taken into account by means of internal damage variables. These damage variables are prescribed to be uniform throughout the thickness of each ply which defines what we call a damage meso-model (Ladevèze, 1986). This play a crucial role for a mesh-independent damage prediction (Ladevèze, 1992,). The single-layer model and its identification, including damage and inelasticity, were previously developed by Ladevèze and Le Dantec (1992).

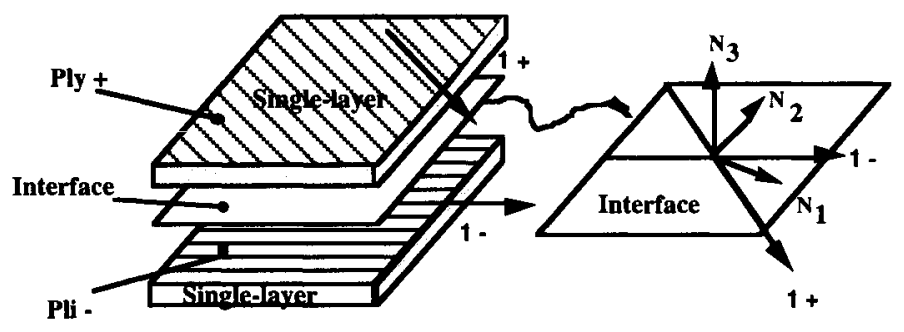

Figure 1. Laminate meso-modelling.

The interlaminar interface is a two-dimensional entity which ensures traction and displacement transfer from one ply to another. Its mechanical behaviour depends on the angles between the fibers of two adjacent layers. Its primary interest is to allow the modelling of more or less progressive degradation of the interlaminar connection (Allix et al. 1985, Allix 1992, Allix and Ladevèze 1996). One consequence of this meso-model is that only two types of cracks are being considered: delamination cracks and orthogonal cracks which extend across the entire thgickness of the layer.

In this paper, attention is being focused on the the interface model and on its use in solving delamination problems: Edge Delamination Tension problems, Fracture Mechanics specimens, holed plates. For several materials, numerical simulations are presented and compared with experimental results.

\section{Interlaminar Interface Modelling}

The effect of the deterioration of the interlaminar connection on its mechanical behaviour is taken into account by means of internal damage variables. The energy per unit area proposed by Allix and Ladevèze (1992) is: 


$$
\mathrm{E}_{\mathrm{D}}=\frac{1}{2}\left[\frac{\left.<-\sigma_{33}\right\rangle_{+}^{2}}{\mathrm{k}_{3}^{0}}+\frac{\left.<\sigma_{33}\right\rangle_{+}^{2}}{\mathrm{k}_{3}^{0}\left(1-\mathrm{d}_{3}\right)}+\frac{\sigma_{32}^{2}}{\mathrm{k}_{2}^{0}\left(1-\mathrm{d}_{2}\right)}+\frac{\sigma_{31}^{2}}{\mathrm{k}_{1}^{0}\left(1-\mathrm{d}_{1}\right)}\right]
$$

where $\mathrm{k}_{\mathrm{i}}^{0}$ is an interlaminar stiffness value and $d_{i}$ the intemal damage indicator associated with its Fracture Mechanics mode, while i corresponds to an orthotropic direction $\mathrm{N}_{\mathrm{i}}$ of the interface (Figure 1). These directions are defined as the bisectors of the angle formed by the fibre directions of the adjacent layers. The damage energy release rates are introduced as:

$$
\mathrm{Y}_{\mathrm{d} 3}=\frac{1}{2} \frac{<\sigma_{33^{2}}{ }^{2}}{\mathrm{k}_{3}^{0}\left(1-\mathrm{d}_{3}\right)^{2}} ; \mathrm{Y}_{\mathrm{d}_{1}}=\frac{1}{2} \frac{\sigma_{31}^{2}}{\mathrm{k}_{1}^{0}\left(1-\mathrm{d}_{1}\right)^{2}} ; \mathrm{Y}_{\mathrm{d}_{2}}=\frac{1}{2} \frac{\sigma_{32}^{2}}{\mathrm{k}_{2}^{0}\left(1-\mathrm{d}_{2}\right)^{2}}
$$

In what follows, an "isotropic" damage evolution law is described. The damage evolution law is assumed to be governed by means of an equivalent damage energy release rate of the following form:

$$
\underline{Y}(t)=\left.\sup \right|_{\tau \leq t}\left[\left(\left(Y_{d_{3}}\right)^{\alpha}+\left(\gamma_{1} Y_{d_{1}}\right)^{\alpha}+\left(\gamma_{2} Y_{d_{2}}\right)^{\alpha}\right)_{\mid \tau}^{1 / \alpha}\right]
$$

The evolution of the damage indicators is thus assumed to be strongly coupled. $\gamma_{1}, \gamma_{2}$ and $\alpha$ are material parameters. A simple damage evolution law is then defined as follows:

$$
d_{3}=d_{1}=d_{2}=\left[\frac{n}{n+1} \frac{\leq \underline{Y}-Y_{o}>_{+}}{Y_{c}-Y_{0}}\right]^{n} \text { if } d_{3}<1, d_{3}=d_{1}=d_{2}=1 \text { otherwise }
$$

wherein a critical value $Y_{c}$ and a threshold value $Y_{0}$ have been introduced. High values of the " $n$ " case correspond to a brittle interface. In Allix and Corigliano (1996), it is shown that the Fracture Mechanics associated with this damage evolution law is:

$$
\left(\frac{\mathrm{G}_{\mathrm{I}}}{\mathrm{G}_{\mathrm{cI}}^{\mathrm{p}}}\right)^{\alpha}+\left(\frac{\mathrm{G}_{\mathrm{II}}}{\mathrm{G}_{\mathrm{cII}}^{\mathrm{p}}}\right)^{\alpha}+\left(\frac{\mathrm{G}_{\mathrm{III}}}{\mathrm{G}_{\mathrm{cIII}}^{\mathrm{p}}}\right)^{\alpha}=1
$$

with:

$$
\mathrm{G}_{\mathrm{cI}}^{\mathrm{p}}=\mathrm{Y}_{\mathrm{c}} ; \mathrm{G}_{\mathrm{cII}}^{\mathrm{p}}=\frac{\mathrm{Y}_{\mathrm{c}}}{\gamma_{1}} ; \mathrm{G}_{\mathrm{cIII}}^{\mathrm{p}}=\frac{\mathrm{Y}_{\mathrm{c}}}{\gamma_{2}}
$$




\section{Fracture Mechanics Tests}

\subsection{Experimental part}

The tests of crack propagation in interlaminar fracture specimens conducted in this work and developed at the AÉROSPATIALE facility in Suresnes (France) are the pure-mode I DCB (Double-Cantilever Beam) Test (De Charentay et al., 1984), the pure-mode II ENF (End-Notched Flexure) Test (Davies et al., 1990) and a mixed-mode test: the MMF (Mixed-Mode Flexure) Test (Russell and Street, 1985). These tests were conducted on M55J/M18 material laminates. In this work, we focus our attention on only the prediction of unidirectional laminate fracture mechanics tests. The mean thickness of a single ply is on the order of $0.1 \mathrm{~mm}$. The tests have been conducted on an INSTRON testing machine at ambient temperature. The displacement rate was fixed at $2 \mathrm{~mm} / \mathrm{min}$ in the DCB test and at $1 \mathrm{~mm} / \mathrm{min}$ in the ENF and MMF tests. In these two latter bending tests, the total useful length was $180 \mathrm{~mm}$.

The critical energy release rates are usually reduced by means of Linear Elastic Fracture Mechanics. The links between Linear Elastic Fracture Mechanics and Damage Mechanics serve to identify the parameters of the interfacial modelling relative to those critical rates. In the DCB test, the mode I critical energy release rate measured for the unidirectional material was $\mathrm{G}_{\mathrm{cI}}^{\mathrm{P}}=113 \mathrm{~J} / \mathrm{m}^{2}$. This value was obtained by derivation of the experimental compliance of the specimen. The mode II critical energy release rate measured in the ENF test provides us with the value of $\gamma_{1}=0.37$. The value of the $\alpha$ parameter was found by means of the mixed-mode test: $\alpha=1.6$ for the $0^{\circ} / 0^{\circ}$ interface.

Remark: In another work (Allix et al. 1997), we emphasize the necessity of taking account of the dissipative phenomena inside the layers, especially when $\theta \neq 0^{\circ}$, because the measured energy release rate cannot be attributed to the debonded interface only.

\subsection{Comparison between predicted values and experimental results for a $0^{\circ} / 0^{\circ}$ interface case}

With the previous measured values of the energy release rate and making use of relations (6) we are able to identify an interface model and then to simulate the response of the different tests. These finite element predictions have been 
conducted with the help of ENDO-STRAT-EF, a three dimensional non-linear finite element code that includes the meso-model (Gornet et al., 1997). Numerical results are mesh-independent; the basic factor behind this is the presence of internal lengths in the meso-modeling. In this work, the same finite element mesh was used for all laminate Fracture Mechanics specimen test predictions. This mesh consisted of 678 elements for each of both arm (layers) and 226 special elements for the interface (Beer, 1985). Here, we will only show the prediction for the DCB and MMF tests.

Figure 2 depicted the correlation obtained between experimental results and finite element predicted values in the case of a DCB specimen. The MMF test specimen is shown in Figure 3. In this mixed mode test, the mode $I$ is dominant. Experimental results and finite element predicted values also exhibit good correlation (Figure 4).

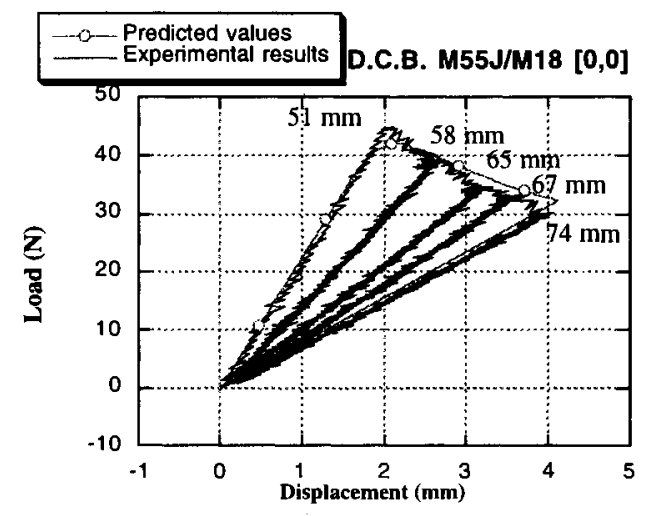

Figure 2. Prediction of a D.C.B. test . Comparison between experimental results and predicted values. The initial crack closure is $\mathrm{a}=50 \mathrm{~mm}$. The growth of the delaminattion area at the end of the test is $23 \mathrm{~mm}$.

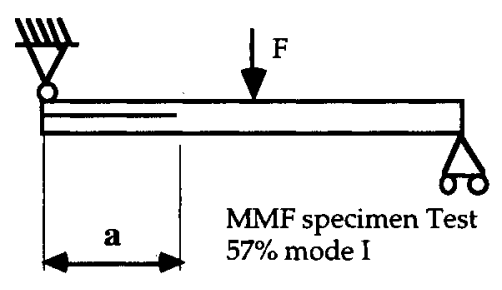

Figure 3. M.M.F. specimen test. The initial crack length has been denoted by "a". 


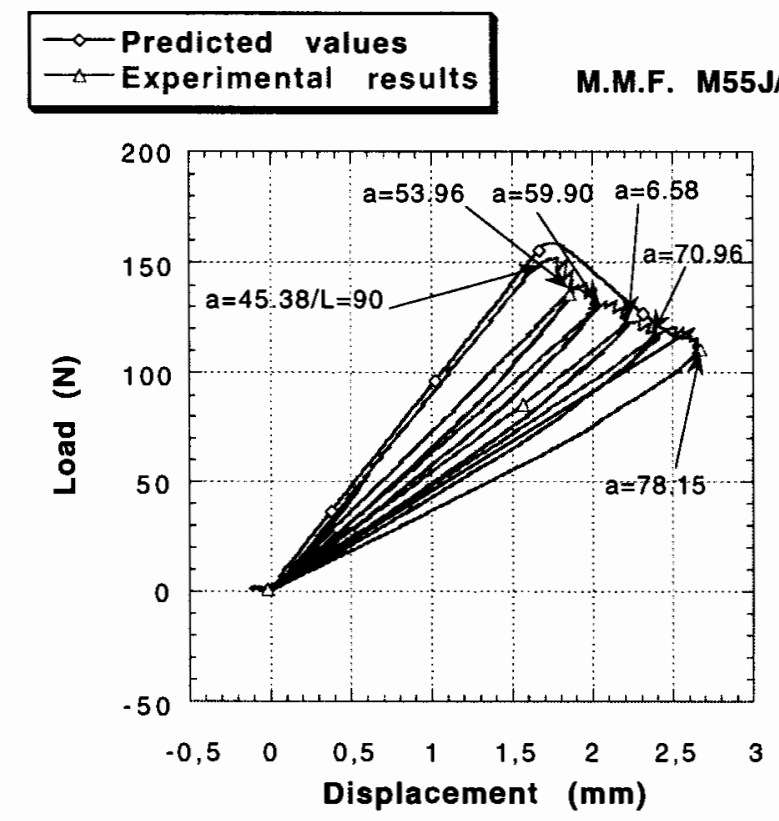

Figure 4. Prediction of an M.M.F. test . Comparison between experimental results and predicted values. The initial crack closure is $a=45 \mathrm{~mm}$. The growth of the delaminattion area at the end of the test is $32.77 \mathrm{~mm}$.

\section{Example of an Edge Delamination Tension specimen}

The specimen under consideration is a $\left(0_{3}, \pm 45_{2}, 90\right) \mathrm{s}$. The edge is straight and the problem to solve can be set as a generalised plain strain problem in a strip perpendicular to the edge. In the previous test the delamination starts on the $\mathrm{O}^{\circ} / \mathrm{O}^{\circ}$ interface and after this initiation point the load can still increase, the maximum value of the applied tension being around four times the initiation load (Allix et al. 1997). Without including the inner layer mechanisms into account in our Finite Element Analysis the initiation and maximum load coincide. Introducing the inner damage mechanisms (namely the transverse cracking), the delamination propagation becomes then stable under increasing tension up to the fiber rupture of the $0^{\circ}$ plies (Gornet et al. 1997). This example shows the necessity of including all the damage mechanisms into the delamination analysis even for quite simple specimens. Figure 5 depictes the state of damage before the final failure of the specimen. 


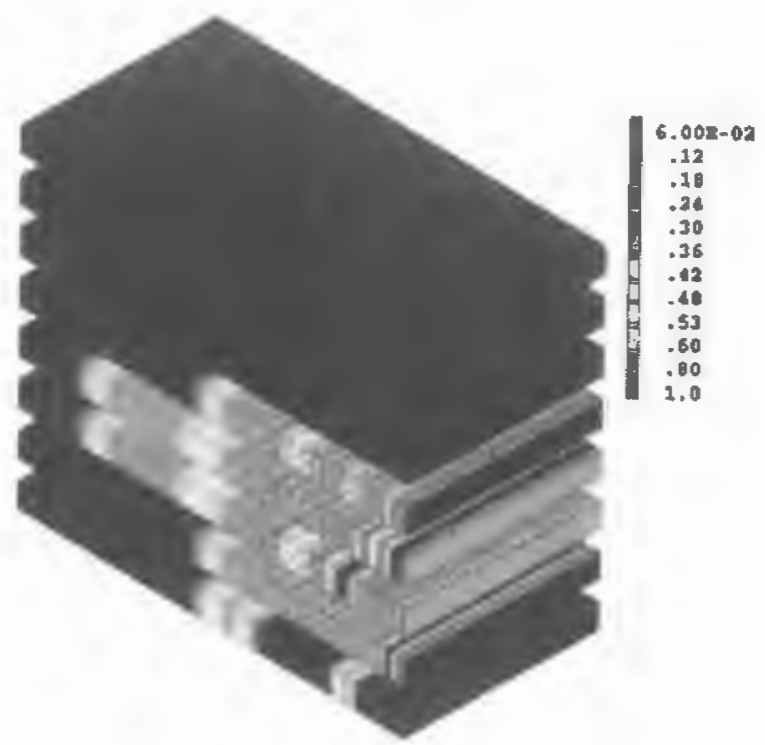

Figure 5. Simulation of the damage state of a $\left(0_{3}, \pm 45_{2}, 90\right)$ s E.D.T. specimen before the final failure.

\section{Damage identification using plates with holes}

More reliable delamination tests would be those on laminated plates with a circular hole. In fact, for such specimens, the delamination crack initiation is reproducible and the growth is often stable within a certain range. The idea herein is to use the first parameter set identified previously as initial data for a global identification using plates with holes. We are just at the beginning of this procedure. Also of interest in this test is the valuable information it providesin terms of the shape and size of the delaminated area revealed by means of X-ray photography (Figure 6). The difficulty herein is that, due to the complexity of the state of stresses, the interpretation of this test requires complex computations (Figure 7). For such tests, a specialized software DSDM (Delamination Simulation by Damage Mechanics) has been previously developed (Allix 1992). 


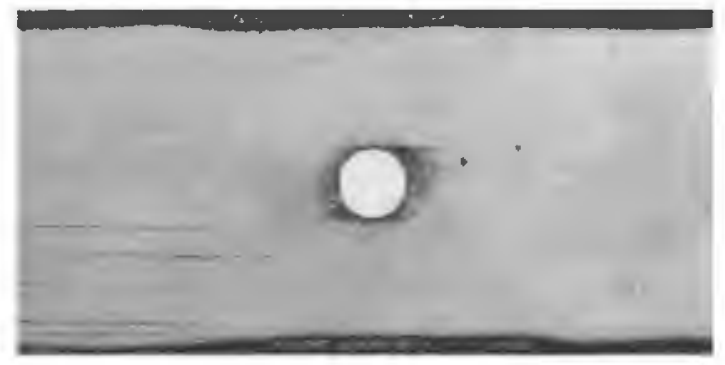

Figure 6. $\left[00_{3} / \pm 45_{2} / 90\right]_{\mathrm{S}} \mathrm{X}$-ray photograph (86\% of the rupture load).

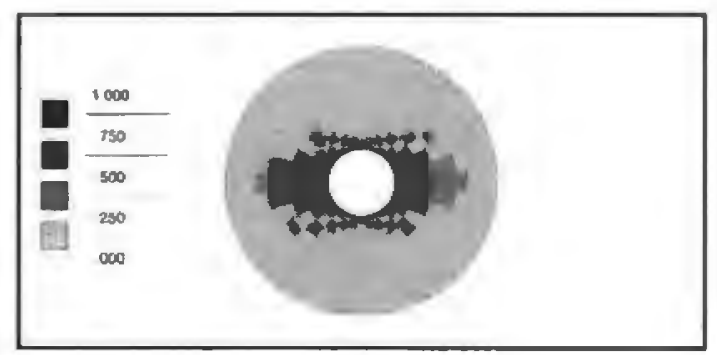

Figure 7. $\mathrm{d}_{3}$ indicator computed at the $0 \%+45^{\circ}$ interface in the $\left[0_{3} / \pm 45_{2} / 90\right]_{\mathrm{S}}$ laminate.

\section{Conclusions}

This work represents the first step towards a global identification of an interface damage model dedicated to delamination prediction. An initial set of parameters was determined using standard initiation and propagation tests conducted on M55J/M18 material specimens. It has been shown that experimental results and finite element predicted values exhibit strong correlation for classical fracture mechanics tests. Lastly, an initial comparison between computation and a holed-specimen test in tension has revealed the interest of using such an approach as a standard identification test.

\section{References}

Allix, O. (1992) Damage analysis of delamination around a hole. New Advances in Computational Structural Mechanics, P. Ladevèze, O. C. Zienkiewicz eds., Elsevier Science Publishers B. V., pp 411-421.

Allix, O., Gilletta D. and Ladevèze, P. (1985) Mechanical behaviour of elementary constituents of laminates, Proceedings I.C.C.M.M. V, San Diego, August 1985. 
Allix, O. and Corigliano, A. (1996) Modeling and simulation of crack-propagation in mixed-modes interlaminar fracture specimens. In International Journal of Fracture 77, pp. 11-140.

Allix, O. and Ladevèze, P. (1992) Interlaminar interface modelling for the prediction of delamination, Comp. Struct., 22:235-242.

Allix, O. and Ladevèze, P. (1996) Damage mechanics of interfacial media: basic aspects, identification and application to delamination. In Damage and Interfacial Debonding in Composites. Studies in applied Mechanics, 44, Eds Allen D. and Voyiadjis G., Elsevier, pp. 167-88.

Allix O., Ladevèze P., Lévêque D., Perret L. (1997) Identification and validation of an interface damage model for delamination prediction, Computational Plasticity, eds Owen D.R.J., Oñate E. \& Hinton E., Barcelone, pp. 1139-1147.

Beer, G. (1985). An isoparamétric joint/interface element for finite element analysis, Int. J. for Numer. Methods Eng., 21, pp. 585-600.

De Charentenay, F.-X., Harry, J.M., Prel, Y.J. and Benzeggagh, M.L. (1984) Characterizing the Effect of Delamination Defect by Mode I Delamination Test. Effect of Defects in Composite Materials, ASTM STP 836, pp 84-103.

Davis P. 1990. Measurement of GIc and GIIc in carbon/epoxy composites, Comp. Sci. \& Technol., 39, pp. 193-205.

Gornet, L. Hochard, C., Ladevèze, P. and Perret, L. (1997), Proceedings Damage and Failure of Interfaces, DFI-1, Vienna, Austria, Sept 22-24.

Ladevèze, P. (1986) Sur la mécanique de l'endommagement des composites, Proceedings of the Fifth French National Colloquium on Composite Materials, JNC 5, C. Bathias \& D. Menkès eds, Pluralis Publication, Paris, pp. 667-683.

Ladevèze, P. (1992) Towards a fracture theory, Proceedings of the third International Conference on Computational Plasticity Part II, D.R.J. OWEN, E. ONATE, E. HINTON ed, Pineridge press, Cambridge U.K., pp. 1369-1400.

Ladevèze, P. and Le Dantec, E. (1992) Damage modelling of the elementary ply for laminated composites, Comp. Sci. \& Technol., 43:257-267.

Russell, A.J. and Street., K.N. (1985) Moisture and temperature effects on the mixedmode delamination fracture of unidirectional graphite/epoxy, Delamination and Debonding of Materials, ASTM STP 876, W.S. Johnson, Ed., pp 349-370. 